\title{
Assessment of Non-Motor Symptoms in Essential Tremor
}

\author{
Tatiana G. Govorova ${ }^{1 *}$; Tatiana E. Popova, $\mathrm{PhD}, \mathrm{ScD}^{1,2}$; Aleksei A. Tappakhov, $\mathrm{PhD}^{1,2}$; \\ Michil E. Andreev ${ }^{1}$ \\ ${ }^{1}$ M.K. Ammosov North-Eastern Federal University \\ ${ }^{2}$ Yakut Science Center of Complex Medical Problems, \\ Yakutsk, the Republic of Sakha (Yakutia), the Russian Federation
}

\begin{abstract}
In the clinical picture of essential tremor (ET), in addition to tremulous hyperkinesis, the importance of non-motor manifestations has recently been discussed. Despite their high occurrence, in most cases these manifestations remain unverified. The purpose of this study was to assess the incidence of non-motor symptoms (NMS) in patients with ET. The study included 3 groups comparable by sex and age. Group 1 (the main group) consisted of 53 patients with ET; Group 2 consisted of 57 patients with Parkinson's disease (PD); Group 3 consisted of 111 individuals without ET or PD, and without burdened heredity for extrapyramidal diseases. In study Groups the distribution by ethnicity was as follows: 22(41.5\%) ethnic Yakuts and 31(58.5\%) ethnic Russians in Group 1, 29(50.9\%) ethnic Yakuts and 28(49.1\%) ethnic Russians in Group 2, and 67(60.4\%) ethnic Yakuts and 44(39.6\%) ethnic Russians in Group 3. All subjects filled out the NMSQuest scale, which contains 30 questions for various groups of NMS. The analysis of NMS using the NMSQues scale in the three study groups showed a similarity between ET plus and PD in non-motor manifestations. The spectrum of NMS in patients with ET plus of both ethnic groups is heterogeneous and prevails in patients of the Russian ethnic group. Thus, Yakut patients with ET plus and PD showed a similarity in the frequency of hyposmia to Russian representatives with ET plus and PD in hyposmia, dysphagia, pain, sadness and restless legs syndrome. Excessive sweating was found in more than $64 \%$ of patients with ET plus of both ethnic groups. The results indicate a similarity in manifestations of ET plus and PD, which is possibly due to both the genetic and phenotypic affinity of these nosologies, and suggests that ET plus can be a transitional form of PD. (International Journal of Biomedicine. 2019;9(4):308-312.)
\end{abstract}

Key Words: essential tremor • Parkinson's disease $・$ non-motor symptoms $\bullet$ NMSQuest

\section{Introduction}

ET is considered the most common disease of the extrapyramidal system, with a slowly progressing and disabling course. ${ }^{(1)}$ A classic manifestation of the disease is a progressive kinetic-postural hand tremor, most often in combination with a tremor in a different location. ET is now considered to be a "syndrome" that can be associated with other symptoms. Based on a new classification of tremor, ${ }^{(2)}$ ET can be classified as Essential Tremor and Essential Tremor plus. ET plus is a tremor with similar characteristics but may have additional neurological signs, such as impaired tandem

*Corresponding author: Tatiana G. Govorova. M.K. Ammosov North-Eastern Federal University, Yakutsk, the Republic of Sakha (Yakutia),the Russian Federation.E-mail: govorovatatyana@, $\underline{\text { mail.ru }}$ gait or memory, dystonia or other mild neurological signs of unknown significance. ${ }^{(2)}$ In the clinical picture of the disease, in addition to tremulous hyperkinesis, the importance of non-motor symptoms (NMS) has recently been discussed. ${ }^{(3)}$ The spectrum of NMS in ET includes cognitive, psychiatric, sensory and other disorders (sleep disturbances, decreased body mass index, decreased quality of life). ${ }^{(3-11)}$ NMS in ET, along with obligate symptoms, make up a common, rather complex phenotype of the disease..$^{(12)}$

A number of authors do not exclude the probability of a manifestation of the disease with NMS. ${ }^{(9,10)}$ Patients with ET are diagnosed with a variety of cognitive impairments: from mild/ moderate impairment to dementia. ${ }^{(4)}$ Psychiatric symptoms of ET include depression, increased anxiety, apathy, and changes in personality traits. ${ }^{(3)}$ In general, studies show that patients with ET are observed with a high frequency of depression, apathy, situational anxiety, and social phobia, ${ }^{(13,15,16)}$ often 
diagnosed with sensory impairment in the form of hearing loss and olfactory dysfunction. ${ }^{(17,18)}$ The spectrum of NMS in ET is supplemented by sleep disturbances in this category of patients. ${ }^{(19)}$

\section{Materials and Methods}

The study included 3 groups comparable by sex and age. Group 1 (the main group) consisted of 53 patients (average age of 62.62 \pm 2.3 years) with ET: 19(35.8\%) men and $34(64.2 \%)$ women. In Group 1, the distribution by ethnicity was as follows: $22(41.5 \%)$ ethnic Yakuts and 31(58.5\%) ethnic Russians. Group 2 consisted of 57 patients (average age of $67.1 \pm 1.02$ years) with Parkinson's disease (PD), including 23(40.4\%) men and 34(59.7\%) women. In Group 2, the distribution by ethnicity was as follows: $29(50.9 \%)$ ethnic Yakuts and 28(49.1\%) ethnic Russians. Group 3 (the control group) consisted of 111 individuals (average age of $63.4 \pm 0.93$ years) without ET or PD, and without burdened heredity for extrapyramidal diseases. In Group 3, the distribution by ethnicity was as follows: 67(60.4\%) ethnic Yakuts and 44(39.6\%) ethnic Russians.

All subjects filled out the NMSQuest scale, which contains 30 questions for various groups of NMS.(20) Each positive answer was scored as 1 point.

Statistical analysis was performed using statistical software package SPSS version 17.0 (SPSS Inc, Chicago, IL). Categorical variables were analyzed using the Chi-square test with the Yates' correction. The critical level of statistical significance for the three groups was determined at $P \leq 0.05 / 3=0.017\left(P_{1-2}, P_{2-3}, P_{1-3}\right)$.

The study was carried out in compliance with Ethical Principles for Medical Research Involving Human Subjects, Adopted by the 18th WMA General Assembly, Helsinki, Finland, June 1964, and amended by the 52nd WMA General Assembly, Edinburgh, Scotland, October 2000. The study was approved by our regional ethics committee. All patients gave their written informed consent.

\section{Results and Discussion}

According to the results of the survey, in Group 1 the most frequent NMSs were nightly urination (64.2\%), excessive sweating $(62.3 \%)$, insomnia $(41.5 \%)$, dizziness (feeling light-headed) $(41.5 \%)$, sadness (39.6\%), constipation (39.6\%), subjective feeling of memory loss (35.8\%), anxiety $(34.0 \%)$, hyposmia $(30.2 \%)$, false urge to urinate $(26.4 \%)$, and incomplete defecation (26.4\%). The analysis revealed statistically significant differences in symptoms, such as hypersalivation, constipation, sexual dysfunction, falls and daytime sleepiness due to their frequent occurrence in patients of Group $2(P<0.017)$. In Group 1, falls were due to tremor of the lower extremities in one person and vertigo in two people. At the same time, statistically significant differences in dysphagia, hyposmia and apathy were found due to their rare frequency in the healthy individuals of Group 3. Patients of Group 1 were characterized by a high frequency of excessive sweating and insomnia, unlike patients of Group 2.
Table 1.

Distribution of NMS of in the study group

\begin{tabular}{|c|c|c|c|c|}
\hline NMS & Group 1 & Group 2 & Group 3 & $P$-value \\
\hline Hypersalivation & $5(9.4 \%)$ & $19(38 \%)$ & $1(2.6 \%)$ & $\begin{array}{l}\mathrm{P}=0.000 \\
\mathrm{P}_{1-2}=0.001 \\
\mathrm{P}^{1-3}=0.234 \\
\mathrm{P}_{2-3}=0.000\end{array}$ \\
\hline Hyposmia & $16(30.2 \%)$ & $24(48 \%)$ & $3(7.7 \%)$ & $\begin{array}{l}\mathrm{P}=0.000 \\
\mathrm{P}_{1-2}=0.064 \\
\mathrm{P}_{1-3}=0.008 \\
\mathrm{P}_{2-3}=0.000\end{array}$ \\
\hline Dysphagia & $14(26.4 \%)$ & $12(24 \%)$ & $2(5.1 \%)$ & $\begin{array}{l}\mathrm{P}=0.026 \\
\mathrm{P}_{1-2}=0.777 \\
\mathrm{P}_{1-3}=0.008 \\
\mathrm{P}_{2-3}=0.015\end{array}$ \\
\hline Nausea. vomiting & $6(11.3 \%)$ & $6(12 \%)$ & $1(2.6 \%)$ & $\mathrm{P}=0.444$ \\
\hline Constipation & $21(39.6 \%)$ & $40(80 \%)$ & $15(38.5 \%)$ & $\begin{array}{l}\mathrm{P}=0.000 \\
\mathrm{P}_{1-2}=0.000 \\
\mathrm{P}_{1-3}=0.909 \\
\mathrm{P}_{2-3}=0.000\end{array}$ \\
\hline Enuresis & $1(1.9 \%)$ & $2(4 \%)$ & 0 & $\mathrm{P}=0.798$ \\
\hline $\begin{array}{l}\text { Incomplete } \\
\text { defecation }\end{array}$ & $14(26.4 \%)$ & 0 & $6(15.4 \%)$ & $\begin{array}{l}\mathrm{P}=0.001 \\
\mathrm{P}_{1-2}=0.000 \\
\mathrm{P}^{1-2}=0.205 \\
\mathrm{P}_{2-3}=0.014\end{array}$ \\
\hline $\begin{array}{l}\text { False urge } \\
\text { to urinate }\end{array}$ & $14(26.4 \%)$ & $7(14 \%)$ & $2(5.1 \%)$ & $\begin{array}{l}\mathrm{P}=0.020 \\
\mathrm{P}_{1-2}=0.118 \\
\mathrm{P}_{1-2}=0.008 \\
\mathrm{P}_{2-3}=0.306\end{array}$ \\
\hline Nocturia & $34(64.2 \%)$ & $22(44 \%)$ & $18(46.2 \%)$ & $\mathrm{P}=0.084$ \\
\hline Unexplained pain & $13(24.5 \%)$ & $1530 \%)$ & $6(15.4 \%)$ & $\mathrm{P}=0.27$ \\
\hline Weight fluctuations & $2(3.8 \%)$ & $7(14 \%)$ & $2(5.1 \%)$ & $\mathrm{P}=0.11$ \\
\hline Memory loss & $19(35.8 \%)$ & $31(62 \%)$ & $19(48.7 \%)$ & $\begin{array}{l}\mathrm{P}=0.03 \\
\mathrm{P}_{1-2}=0.008 \\
\mathrm{P}^{1-3}=0.215 \\
\mathrm{P}_{2-3}=0.210\end{array}$ \\
\hline Apathy & $14(26.4 \%)$ & $13(26 \%)$ & $3(7.7 \%)$ & $\mathrm{P}=0.054$ \\
\hline Hallucinations & $3(5.7 \%)$ & $3(6 \%)$ & 0 & $\mathrm{P}=0.3$ \\
\hline Difficulty concentrating & $10(18.9 \%)$ & $14(28 \%)$ & $7(17.9 \%)$ & $\mathrm{P}=0.42$ \\
\hline Sadness & $21(39.6 \%)$ & $22(44 \%)$ & $6(15.4 \%)$ & $\begin{array}{l}\mathrm{P}=0.000 \\
\mathrm{P}_{1-2}=0.652 \\
\mathrm{P}_{1-3}=0.012 \\
\mathrm{P}_{2-3}=0.004\end{array}$ \\
\hline Anxiety & $18(34.0 \%)$ & $19(38 \%)$ & $13(33.3 \%)$ & $\mathrm{P}=0.88$ \\
\hline $\begin{array}{l}\text { Hypoactive sexual } \\
\text { desire disorder }\end{array}$ & $4(7.5 \%)$ & $32(64 \%)$ & $(20.5 \%)$ & $\begin{array}{l}\mathrm{P}=0.000 \\
\mathrm{P}_{1-2}=0.000 \\
\mathrm{P}^{1-3}=0.068 \\
\mathrm{P}_{2-3}=0.000\end{array}$ \\
\hline $\begin{array}{l}\text { Sexual dysfunction } \\
\text { without sexual } \\
\text { desire disorder }\end{array}$ & $2(3.8 \%)$ & $14(28 \%)$ & 0 & $\begin{array}{l}\mathrm{P}=0.000 \\
\mathrm{P}_{1-2}=0.001 \\
\mathrm{P}^{1-2}=0.615 \\
\mathrm{P}_{2-3}=0.000\end{array}$ \\
\hline
\end{tabular}


Table 1.

\section{Distribution of NMS of in the study group (Continued)}

\begin{tabular}{|c|c|c|c|c|}
\hline NMS & Group 1 & Group 2 & Group 3 & $P$-value \\
\hline Feeling light-headed & $22(41.5 \%)$ & $28(56 \%)$ & $15(38.5 \%)$ & $\mathrm{P}=0.189$ \\
\hline Falls & $3(5.7 \%)$ & $11(22 \%$ & $2(5.1 \%)$ & $\begin{array}{l}\mathrm{P}=0.012 \\
\mathrm{P}_{1-2}=0.016 \\
\mathrm{P}_{1-3}=0.724 \\
\mathrm{P}_{2-3}=0.025\end{array}$ \\
\hline $\begin{array}{l}\text { Excessive daytime } \\
\text { sleepiness }\end{array}$ & $11(20.8 \%)$ & $26(52 \%)$ & $9(23.1 \%)$ & $\begin{array}{l}\mathrm{P}=0.001 \\
\mathrm{P}_{1-2}=0.001 \\
\mathrm{P}_{1-3}=0.790 \\
\mathrm{P}_{2-3}=0.006\end{array}$ \\
\hline Imsomnia & $22(41.5 \%)$ & $10(20 \%)$ & $16(41 \%)$ & $\begin{array}{l}\mathrm{P}=0.037 \\
\mathrm{P}_{1-2}=0.018 \\
\mathrm{P}_{1-3}=0.964 \\
\mathrm{P}_{2-3}=0.030\end{array}$ \\
\hline Vivid dreaming & $11(20.8 \%)$ & $10(20 \%)$ & $9(23.1 \%)$ & $\mathrm{P}=0.936$ \\
\hline Sleep-talking & $10(18.9 \%)$ & $14(28 \%)$ & $4(10.2 \%)$ & $\mathrm{P}=0.111$ \\
\hline Restless legs syndrome & $9(17.0 \%)$ & $10(20 \%)$ & $8(20.5 \%)$ & $\mathrm{P}=0.891$ \\
\hline Swelling (edema) & $12(22.6 \%)$ & $6(12 \%)$ & $5(12.8 \%)$ & $\mathrm{P}=0.273$ \\
\hline Excessive sweating & $33(62.3 \%)$ & $8(16 \%)$ & $4(10.2 \%)$ & $\begin{array}{l}\mathrm{P}=0.000 \\
\mathrm{P}_{1-2}=0.000 \\
\mathrm{P}_{1-3}=0.000 \\
\mathrm{P}_{2-3}=0.431\end{array}$ \\
\hline Double vision & $4(7.5 \%)$ & $1(2 \%)$ & $1(2.6 \%)$ & $\mathrm{P}=0.313$ \\
\hline Illusions & $2(3.8 \%)$ & 0 & 0 & $\mathrm{P}=0.658$ \\
\hline
\end{tabular}

Symptoms such as hyposmia, apathy, and dysphagia were equally common in Groups 1 and 2 (Table 1).

Considering the presence of other extrapyramidal phenomena in the clinical aspect of ET, we also evaluated NMS in patients with ET plus in the ethnic aspect. Patients with ET plus of the Yakut and Russian ethnic groups comprised $17 / 45(37.8 \%)$ and $28 / 45(62.2 \%)$ patients, respectively. Group 2 included 29/57(50.9\%) ethnic Yakuts and 28/57(49.1\%) ethnic Russians. Group 3 consisted of 35/57(61.4\%) ethnic Yakuts and 22/57(38.6\%) ethnic Russians.

Statistically significant differences were shown between the 3 study groups for such NMS as hypersalivation, hyposmia, constipation, sexual dysfunction, and daytime sleepiness, due to their frequent occurrence in ethnic Yakuts of Group 2 (Figure 1). We found no statistically significant difference in the incidence of hyposmia in patients with ET plus and patients with PD of the Yakut ethnic group.

In patients with ET plus of the Russian ethnic group, sweating was diagnosed statistically significantly more often compared to Groups 2 and $3(P<0.017)$ (Table 2). Statistical differences were identified for apathy (35.7\% in Group 1 and $39.3 \%$ in Group 2) compared to Group $3(0 \%)$.
At the same time, constipation, difficulty concentrating, and sexual dysfunction were statistically significantly more common in patients of Group 2 compared to Group 1. Patients with ET and PD were similar in such NMS as hypersalivation, hyposmia, dysphagia, pain, sadness, and restless legs syndrome $(P>0.017)$.

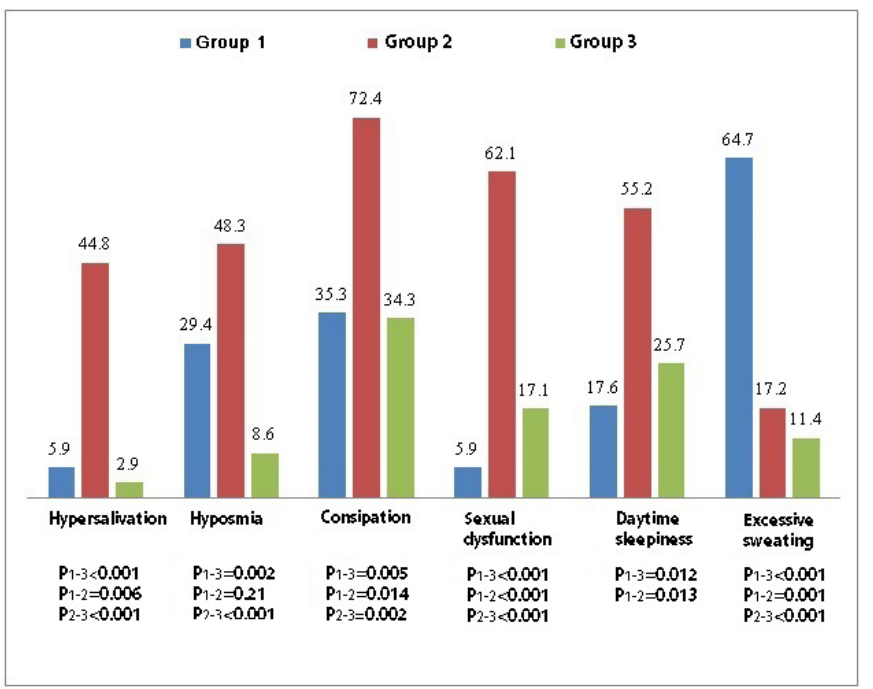

Fig. 1. The spectrum of NMS in the Yakut representatives of the study groups

Table 2 .

The spectrum of NMS in the Russian representatives of the study groups

\begin{tabular}{|c|c|c|c|c|}
\hline NMS & $\underset{(n=28)}{\text { Group } 1}$ & $\begin{array}{c}\text { Group 2 } \\
(\mathrm{n}=28)\end{array}$ & $\begin{array}{c}\text { Group } 3 \\
(\mathrm{n}=22)\end{array}$ & $P$-value \\
\hline Hypersalivation & $2(7.1)$ & $9(32.1)$ & $1(4.5)$ & $\begin{array}{l}\mathrm{P}=0.031 \\
\mathrm{P}_{1-2}=0.019 \\
\mathrm{P}_{1-3}=0.813 \\
\mathrm{P}_{2-3}=0.039\end{array}$ \\
\hline Hyposmia & $9(32.1)$ & $14(50)$ & $2(9.1)$ & $\begin{array}{l}\mathrm{P}=0.009 \\
\mathrm{P}_{1-2}=0.174 \\
\mathrm{P}_{1-3}=0.108 \\
\mathrm{P}_{2-3}=0.002\end{array}$ \\
\hline Dysphagia & $10(35.7)$ & $13(46.4)$ & $2(9.1)$ & $\begin{array}{l}\mathrm{P}=0.017 \\
\mathrm{P}_{1-2}=0.415 \\
\mathrm{P}_{1-3}=0.029 \\
\mathrm{P}_{2-3}=0.004\end{array}$ \\
\hline Nausea. vomiting & $2(7.1)$ & $8(28.6)$ & 0 & $\begin{array}{l}\mathrm{P}=0.024 \\
\mathrm{P}_{1-2}=0.036 \\
\mathrm{P}_{1-3}=0.581 \\
\mathrm{P}_{2-3}=0.019\end{array}$ \\
\hline Constipation & $13(46.4)$ & $23(82.1)$ & $7(31.8)$ & $\begin{array}{l}\mathrm{P}=0.001 \\
\mathrm{P}_{1-2}=0.005 \\
\mathrm{P}_{1-3}=0.295 \\
\mathrm{P}_{2-3}=0.000\end{array}$ \\
\hline False urges to urinate & $8(28.6)$ & $3(10.7)$ & 0 & $\begin{array}{l}\mathrm{P}=0.042 \\
\mathrm{P}_{1-2}=0.093 \\
\mathrm{P}_{1-3}=0.019 \\
\mathrm{P}_{2-3}=0.325\end{array}$ \\
\hline
\end{tabular}


Table 2 .

The spectrum of NMS in the Russian representatives of the study groups (Continued)

\begin{tabular}{|c|c|c|c|c|}
\hline NMS & $\underset{(n=28)}{\text { Group } 1}$ & $\underset{(n=28)}{\text { Group }} 2$ & $\begin{array}{c}\text { Group } 3 \\
(\mathrm{n}=22)\end{array}$ & $P$-value \\
\hline Unexplained pain & $7(25.0)$ & $13(46.4)$ & $2(9.1)$ & $\begin{array}{l}\mathrm{P}=0.013 \\
\mathrm{P}_{1-2}=0.094 \\
\mathrm{P}_{1-3}=0.279 \\
\mathrm{P}_{2-3}=0.011\end{array}$ \\
\hline Apathy & $10(35.7)$ & $11(39.3)$ & 0 & $\begin{array}{l}\mathrm{P}=0.005 \\
\mathrm{P}_{1-2}=0.783 \\
\mathrm{P}_{1-3}=0.008 \\
\mathrm{P}_{2-3}=0.004\end{array}$ \\
\hline Difficulty concentrating & $5(17.8)$ & $15(53.6)$ & $2(9.1)$ & $\begin{array}{l}\mathrm{P}=0.001 \\
\mathrm{P}_{1-2}=0.005 \\
\mathrm{P}_{1-3}=0.634 \\
\mathrm{P}_{2-3}=0.001\end{array}$ \\
\hline Sadness & $14(50.0)$ & $17(60.7)$ & $4(18.2)$ & $\begin{array}{l}\mathrm{P}=0.009 \\
\mathrm{P}_{1-2}=0.420 \\
\mathrm{P}_{1-3}=0.020 \\
\mathrm{P}_{2-3}=0.002\end{array}$ \\
\hline $\begin{array}{l}\text { Sexual dysfunction } \\
\text { without sexual desire } \\
\text { disorder }\end{array}$ & $2(7.1)$ & $14(50.0)$ & $8(36.4)$ & $\begin{array}{l}\mathrm{P}=0.002 \\
\mathrm{P}_{1-2}=0.000 \\
\mathrm{P}^{1-3}=0.027 \\
\mathrm{P}_{2-3}=0.335\end{array}$ \\
\hline Falls & $3(10.7)$ & $8(28.6)$ & 0 & $\begin{array}{l}\mathrm{P}=0.042 \\
\mathrm{P}_{1-2}=0.093 \\
\mathrm{P}_{1-3}=0.325 \\
\mathrm{P}_{2-3}=0.019\end{array}$ \\
\hline Restless legs syndrome & $5(17.8)$ & $11(39.3)$ & $1(4.5)$ & $\begin{array}{l}\mathrm{P}=0.01 \\
\mathrm{P}_{1-2}=0.076 \\
\mathrm{P}^{1-3}=0.318 \\
\mathrm{P}_{2-3}=0.004\end{array}$ \\
\hline Excessive sweating & $18(64.3)$ & $8(28.6)$ & $2(9.1)$ & $\begin{array}{l}\mathrm{P}=0.000 \\
\mathrm{P}_{1-2}=0.007 \\
\mathrm{P}_{1-3}=0.000 \\
\mathrm{P}_{2-3}=0.176\end{array}$ \\
\hline
\end{tabular}

\section{Conclusion}

Thus, analysis of non-motor symptoms using the NMSQues scale in the three study groups showed a similarity between ET plus and Parkinson's disease in non-motor manifestations. The spectrum of non-motor symptoms in patients with ET plus of both ethnic groups is heterogeneous and prevails in patients of the Russian ethnic group. Thus, Yakut patients with ET plus and Parkinson's disease showed a similarity in the frequency of hyposmia to Russian representatives with ET plus and Parkinson's diseasein hyposmia, dysphagia, pain, sadness and restless legs syndrome. Excessive sweating was found in more than $64 \%$ of patients with ET plus of both ethnic groups. The results indicate a similarity in manifestations of ET plus and Parkinson's disease, which is possibly due to both the genetic and phenotypic affinity of these nosologies, and suggests that ET plus can be a transitional form of Parkinson's disease.

\section{Competing Interests} interests.

The authors declare that they have no competing

\section{Sources of Funding}

The reported study was funded by RFBR, project number 19-315-90007

\section{References}

1. Louis ED. Essential tremor and the cerebellum. Handb Clin Neurol. 2018;155:245-258. doi: 10.1016/B978-0-44464189-2.00016-0.

2. Bhatia KP, Bain P, Bajaj N, Elble RJ, Hallett M, Louis ED; Tremor Task Force of the International Parkinson and Movement Disorder Society. Consensus Statement on the classification of tremors. from the task force on tremor of the International Parkinson and Movement Disorder Society. Mov Disord. 2018 Jan;33(1):75-87. doi: 10.1002/mds.27121.

3. Louis ED. Non-motor symptoms in essential tremor: A review of the current data and state of the field. Parkinsonism Relat Disord. 2016; 22 Suppl 1:115-8. doi: 10.1016/j. parkreldis.2015.08.034

4. Janicki SC, Cosentino S, Louis ED. The cognitive side of essential tremor: what are the therapeutic implications? Ther Adv Neurol Disord. 2013;6(6):353-68. doi: 10.1177/1756285613489591.

5. Jhunjhunwala K, Pal PK. The Non-motor Features of Essential Tremor: A Primary Disease Feature or Just a Secondary Phenomenon? Tremor Other Hyperkinet Mov (NY). 2014;4:255. doi: 10.7916/D8D798MZ

6. Ondo WG, Sutton L, Dat Vuong K, Lai D, Jankovic J. Hearing impairment in essential tremor. Neurology. 2003.61(8):1093-7.

7. Lorenz D, Schwieger D, Moises H, Deuschl G. Quality of life and personality in essential tremor patients. Mov Disord. 2006;21(8):1114-8.

8. Barut BO, Tascilar N, Varo A. Sleep Disturbances in Essential Tremor and Parkinson Disease: A Polysomnographic Study. J Clin Sleep Med. 2015;11(6):655-62. doi: 10.5664/ jcsm. 4778 .

9. Chandran V, Pal PK. Essential tremor: beyond the motor features. Parkinsonism Relat Disord. 2012;18(5):407-13. doi: 10.1016/j.parkreldis.2011.12.003.

10. Gerbin M, Viner AS, Louis ED. Sleep in essential tremor: a comparison with normal controls and Parkinson's disease patients. Parkinsonism Relat Disord. 2012 Mar;18(3):279-84. doi: 10.1016/j.parkreldis.2011.11.004.

11. Sánchez-Ferro Á, Benito-León J, Louis ED, Contador I, Hernández-Gallego J, Puertas-Martín V, Bermejo-Pareja F. Cognition in non-demented Parkinson's disease vs essential tremor: A population-based study. Acta Neurol Scand. 2017;136(5):393-400. doi: 10.1111/ane.12752.

12. Walterfang $M$, van de Warrenburg BP. Cognitive impairment in "Other" movement disorders: hidden defects and valuable clues. Mov Disord. 2014;29(5):694-703. doi: $10.1002 / \mathrm{mds} .25849$

13. Sengul Y, Sengul HS, Yucekaya SK, Yucel S, Bakim B, Pazarcı NK, Özdemir G. Cognitive functions, fatigue, 
depression, anxiety, and sleep disturbances: assessment of nonmotor features in young patients with essential tremor. Acta Neurol Belg. 2015;115(3):281-7. doi: 10.1007/s13760014-0396-6.

14. Benito-León J, Louis ED, Bermejo-Pareja F. Short sleep duration heralds essential tremor: a prospective, populationbased study. Mov Disord. 2013;28(12):1700-7. doi: 10.1002/ mds. 25590

15. Lee SM, Kim M, Lee HM, Kwon KY, Koh SB. Nonmotor symptoms in essential tremor: Comparison with Parkinson's disease and normal control. J Neurol Sci. 2015;349(1-2):16873. doi: 10.1016/j.jns.2015.01.012.

16. Louis ED, Barnes L, Albert SM, Cote L, Schneier FR, Pullman SL, et al. Correlates of functional disability in essential tremor. Mov Disord. 2001;16(5):914-20.

17. Yilmaz NH, Akbostanci MC, Yilmaz N. Sensorineural
Hearing Loss in Non-depressed Essential Tremor Cases and Controls: A Clinical and Audiometric Study. Tremor Other Hyperkinet Mov (N Y). 2015;5:281. doi: 10.7916/ D8XW4HKQ.

18. Louis ED, Bromley SM, Jurewicz EC, Watner D. Olfactory dysfunction in essential tremor: A deficit unrelated to disease duration or severity. Neurology. 2002; 59(10):1631-3.

19. Louis ED, Faust PL, Vonsattel JP, Honig LS, Rajput A, Robinson CA, et al. Neuropathological changes in essential tremor: 33 Cases compared with 21 controls. Brain. 2007;130(Pt 12):3297-307.

20. Chaudhuri KR, Martinez-Martin P, Schapira AH, Stocchi F, Sethi K, Odin P, et al. International multicenter pilot study of the first comprehensive self-completed nonmotor symptoms questionnaire for Parkinson's disease: The NMSQuest study. Mov Disord. 2006;21(7):916-23. 